\section{Fertile Meetings}

\section{from a Correspondent}

THe Society for the Study of Fertility held a successful conference at Newcastle upon Tyne from July 9-13. The symposia, although informally organized, were well attended. Altogether there were three half-day symposia devoted to intersexuality, uterine factors affecting fertility and water metabolism in pregnancy.

The symposium on intersexuality did more to confuse than to clarify. Dr J. L. Hammerton demonstrated that phenotypically male goats may be genetically female and lack a $Y$ chromosome. For bovine freemartins, Dr S. Ohno pointed out that it is no longer possible to accept that the female foetus is masculinized by sex hormones produced by a male twin, and Dr Patricia Jacobs described a case of a pair of monozygotic human twins with $X Y / X O$ mosaicism where one developed as a boy and the other as a Turner's syndrome girl. Thus the phenotypic sex of an individual is determined to a large extent by the genetic sex of the gonad itself.

The symposium on uterine factors affecting fertility concentrated more on a review of the existing information than on the presentation of new data. Dr J. D. Biggers described the effects of ageing uteri and ageing ova on reproductive potential, and Dr J. M. Bedford discussed the different properties of the uterus and the fallopian tube of the rabbit in the capacitation of spermatozoa. J. H. Marston drew together information on the mode of action of intra-uterine devices in primates, laboratory animals and farm animals, and the diversity of mechanisms producing infertility was more impressive than any common theme. The idea that infertility in monkeys is caused by an increased rate of tubal transport of the unfertilized ovum no longer seems tenable.

Water metabolism is not at first sight the most exciting of topics for a reproductive physiologist, but Dr F. E. Hytten and his colleagues from Newcastle held the interest of the audience. It scems still to be unclear to what extent oedema of pregnancy in women may be considered a normal physiological process and to what extent it is pathological. Dr A. D. Dewar gave a lucid and well reasoned account of the weight gain of pregnancy induced by progesterone in mice. Although this can be produced by progesterone injections to non-pregnant females, it cannot, for some curious reason, be elicited in male mice.

\section{Bigger Fish}

\section{from a Correspondent}

A sUCCESSFUL conference on river fisheries was held at the University of Southampton on July 16-17 and was organized by $\mathrm{Mr}$ W. J. Fairbairn of the Department of Zoology, Mr L. S. Wright of the Hampshire River Authority, and Mr D. W. Cross of the Cornwall River Authority. Much of the time of the conference was concerned with the maintenance and management of fisheries - a particularly appropriate topic in view of the urgent need for the development of potential sources of food.

Dr D. H. Mills of the Department of Forestry at Edinburgh dealt with the survival, in some Scottish strcams, of salmon fry reared in hatcheries. He pointed out that a high rate of stocking could be wasteful of fry and that the ideal concentration at which to aim was 2-5 fry per square metre. The density of the populations of trout in the streams was important because trout are predators of salmon fry. Dr Mills emphasized that artificial stocking served little purpose where spawning took place naturally because of the high wastage rate among salmon fry-between 0.5 and 1.5 million fry were necessary to produce only 150 adult salmon.

Mr M. J. Bulleid of the Central Electricity Generating Board described the strict daily routine necessary in hatcheries-cleanliness, knowledge of population density, strict control of growth rate by means of food supply and a good supply of water are all essential. Dr D. Cragg-Hine from the same organization described how the methods being used in the Netherlands for the rearing of coarse fish might be relevant in the future to the development in Britain of coarse fish as a source of food. Dr W. R. Munro of the Freshwater Fisheries Laboratory at Pitlochry said that at present there is no evidence that the Greenland salmon fishery is harming the salmon fisheries of North Europe. For one thing, salmon tagged in Greenland had been recovered in Canada, Ireland and Scotland, which showed that some of the Greenland fish did return to the spawning populations of other fisheries. Moreover, since the Greenland fishery reached its peak in 1964, catches in the Scottish salmon fishery had been better than previously.

The population dynamics of river fish were dealt with by E. D. Le Cren of the Freshwater Biological Association River Laboratory, who pointed out that the production of trout in a chalk stream was often no more than in a mountain beck but that chalk streams tended to contain a few very large fish and becks many small ones. In an account of the flow of energy in freshwater ecosystems, Dr M. E. Varley of the Department of Zoology at Oxford argued that the efficiency with which pike are able to convert the flesh of minnows amounts to 50 per cent. In general, she concluded, it is easier to cultivate one species of fish than to maintain a mixed population of species because, in these circumstances, optimum conditions for one species could be maintained and maximum productivity thus attained.

\section{Rust Fungus Cultured}

ONE of the topics of discussion during the second week of the first International Congress of Plant Pathology, which ended at Imperial College on July 26, has been obligate parasites and, in particular, efforts to culture them away from the host plant. Successful cultures provide the opportunity for close examination of the growth of the parasite, and, if the need for host tissue can be obviated, there is the possibility of investigating the biochemical nature of the part played by the parasite in its relationship with the host. There is also the prospect of providing geneticists with permanent cultures for use as breeding material in the development of resistant strains of the host species.

There was therefore considerable interest and excitement when Dr K. J. Scott of the University of Sydney reported his success in culturing Puccinia graminis, the rust fungus which causes so much damage to wheat 